\title{
Numerical Simulation Analysis of Collapse Process of Isolated Structure in Strong Earthquakes
}

\author{
Yue Ren ${ }^{1, *}$, Ruidong Wang ${ }^{2}$, Wenguang $\mathrm{Liu}^{3}$, and Wenfu $\mathrm{He}^{3}$ \\ ${ }^{1}$ School of Architecture Economics and Engineering Management, Hubei Business College, 430079 Wuhan, China \\ ${ }^{2}$ Shanghai Jiuxuan Engineering Technology Co. Ltd, 200434 Shanghai, China \\ ${ }^{3}$ Department of Civil Engineering, Shanghai University, 200444 Shanghai, China
}

\begin{abstract}
In this paper, the Abaqus model of an 8 layer isolation structure is established, and the connector element provided in the software is used to simulate the stiffness multilinearity in the horizontal and vertical direction of the isolation bearing. In the numerical analysis, six kinds of working conditions are set up to compare the vertical displacement, the peak acceleration and the interlayer displacement etc, and the effect of bearing failure on the superstructure is obtained.
\end{abstract}

\section{Introduction}

Under the action of earthquakes, especially strong earthquakes, the traditional buildings are very easy to cause the continuous collapse or overturn. In previous earthquakes, it has been proved that this situation is extremely possible, so the actual seismic capacity of the structure should have some redundancy, and it is still necessary to ensure that there is no excessive deformation ${ }^{[1]}$. By prolonging the self-vibration period of the structure, the isolation layer can dissipate part of the seismic energy, so it often performs better than the ordinary structure in the earthquake. Although there have been no cases of collapse or overturn of isolated buildings under earthquake action so far, it is necessary to study the damage of isolation bearing and the effect of the failure of isolation layer on the collapse of the structure in strong earthquakes.

The failure of isolation bearings can be considered from two aspects: horizontal and vertical mechanical properties. In previous studies, we thought that when the deformation of the isolator in horizontal direction was more than $350 \%$, the internal rubber and steel plate would break away and destroy. And with the increase of the depth-width ratio, the overturning moment of the structure increases gradually, which can easily cause the eccentricity of the isolation layer, and the local isolation bearing may be damaged by the tensile force.

\section{Main parameters of the finite element model}

\subsection{Damage model of isolation bearing}

\subsubsection{Simplified model of isolation bearing}

\footnotetext{
* Corresponding author: 909118438@qq.com
}

According to the reference [2], the stiffness of the isolation bearing is hardening in the case of large deformation in the horizontal direction. Referring to reference [3-4], the constitutive relation of the horizontal direction of the isolation bearing is presented in Figure 1.

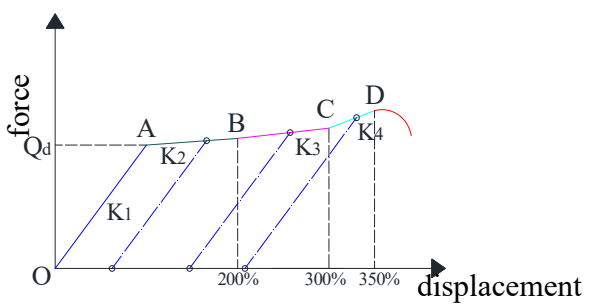

Fig.1 Horizontal direction constitutive relation of isolation bearing

$K_{1}$ is the elastic stiffness of the isolation bearing before yield, $K_{2}$ is the post yield stiffness of the isolation bearing, $K_{3}$ is the stiffness of the first strengthening section (shear strain at $200 \% \sim 300 \%$ ), and $K_{4}$ is the stiffness of the isolation bearing in the second reinforcement section (shear strain at 300\% 350\%). Considering the production level of the actual isolation bearing and the safety of the isolated building, when the shear strain of the isolation bearing is more than $350 \%$, it is considered that the isolation bearing is damaged and withdrew from the work. The specific parameters are shown in Table 1.

Table 1. Horizontal stiffness

\begin{tabular}{|c|c|c|c|c|}
\hline & $\mathrm{A}$ & $\mathrm{B}$ & $\mathrm{C}$ & $\mathrm{D}$ \\
\hline Force $/ \mathrm{kN}$ & 42.724 & 176.083 & 278.568 & 449.375 \\
\hline Displacement mm & 3.877 & 161.2 & 241.8 & 282.1 \\
\hline & $K_{1}$ & $K_{2}$ & $K_{3}$ & $K_{4}$ \\
\hline Stiffness $(\mathrm{kN} / \mathrm{mm})$ & 11.019 & 0.848 & 1.272 & 4.238 \\
\hline
\end{tabular}

The specific parameters are shown in Table 2, and the vertical constitutive relation of the isolation bearing is shown in Figure 2. 
Table 2. Vertical stiffness

\begin{tabular}{|c|c|c|}
\hline & $K_{\mathrm{c}}$ & $K_{\mathrm{t}}$ \\
\hline Stiffness $/(\mathrm{kN} / \mathrm{mm})$ & 1816.3 & 233.15 \\
\hline & \multicolumn{2}{|c|}{} \\
\hline
\end{tabular}

Fig.2 Vertical direction constitutive relation of isolation bearing

According to the above constitutive relation, it is set that when the horizontal displacement of the support exceeds $350 \%$ shear strain, that the failure occurs after more than $0.2821 \mathrm{~m}$, the horizontal stiffness is not continued. Failure in vertical direction is coupled with failure in horizontal direction, which means that vertical direction will no longer provide vertical stiffness after failure in horizontal direction.

\subsubsection{Connection unit of isolation bearing}

The connector unit in Abaqus can accurately simulate the mechanical properties of the isolation bearing in the horizontal and vertical direction by defining the multiline stiffness in the horizontal and vertical direction, so as to simplify the simulation and analysis. Connector unit can define a variety of behavior patterns, and can also define the behavior of a variety of connection units on relative motion components. In this paper, elastic behavior, plastic behavior and damage behavior pattern are used to simulate the work of isolation bearing and the situation after destruction. At the same time, considering the actual force condition, it is necessary to set up the interconnections between components correctly, and use the Cartesian attribute in the basic translation connection property and the Align attribute in the basic rotation connection attribute.

\subsection{Damage model of concrete}

The damage plasticity model of concrete, which is a continuum damage model based on plasticity is selected in Abaqus. It uses isotropic damage elasticity, isotropic stretch and compression plastic to represent the inelastic behavior of concrete, and assumes that the two main failure mechanisms of the concrete material conforms to the core problem of concrete structure modeling. The model can be applied to unidirectional loading, cyclic loading and dynamic loading with s good convergence. In this paper, concrete compression and tensile damage factors are used to judge the damage according to reference [7-9]. It is generally believed that when the damage factor exceeds 0.9 , it can be confirmed that the concrete exceeds the limit compression or tension state.

\section{Establishment of the finite element model}

\subsection{General situation}

The main building on the ground is 8 stories, with a height of $3 \mathrm{~m}$ and a total height of $24 \mathrm{~m}$. The total construction area is about $1024 \mathrm{~m}^{2}$, and the plane is rectangular, $16 \mathrm{~m}$ long and $8 \mathrm{~m}$ wide. The structure adopts isolation design, and the seismic fortification intensity is set to 8 degrees. The basic seismic acceleration value of the design is $0.3 \mathrm{~g}$, and the site category is II class.

In order to control the surface pressure of each isolation bearing in $8 \mathrm{Mpa}$, and the ratio of flexion-weight is controlled around 3\%, 6 circular GZY400 isolation bearings(LRB400) are selected, as shown in Figure 3. The basic mechanical properties are shown in Table 3.

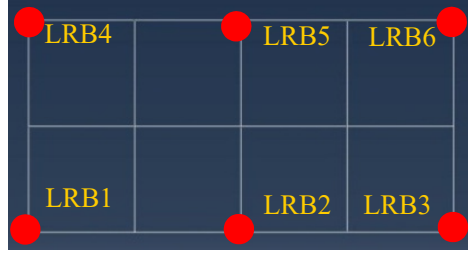

Fig.3. LRB400 arrangement plan

Table 3. Parameters of Basic mechanical properties

\begin{tabular}{|c|c|c|c|c|}
\hline Type & $\begin{array}{c}\text { Yield } \\
\text { force } \\
/ \mathrm{kN}\end{array}$ & $\begin{array}{c}\text { Post-yielding } \\
\text { stiffness } \\
/(\mathrm{kN} / \mathrm{mm})\end{array}$ & $\begin{array}{c}\text { Vertical } \\
\text { compression } \\
\text { stiffness } \\
/(\mathrm{kN} / \mathrm{mm})\end{array}$ & $\begin{array}{c}\text { Vertical } \\
\text { tensile } \\
\text { stiffness } \\
/(\mathrm{kN} / \mathrm{mm})\end{array}$ \\
\hline LRB400 & 42.724 & 0.848 & 1816.300 & 233.150 \\
\hline
\end{tabular}

The whole structure is shown in Figure 3. The green part is the superstructure, the red part is the isolation upper plate, and the gray part is the ground. The isolation bearing unit is connected between the upper plate and the ground. Because the mechanical behavior of connector is not related to the height of setting and the height of each isolation bearing is $1 \mathrm{~m}$ in order to be more obvious to observe the failure of the bearing.

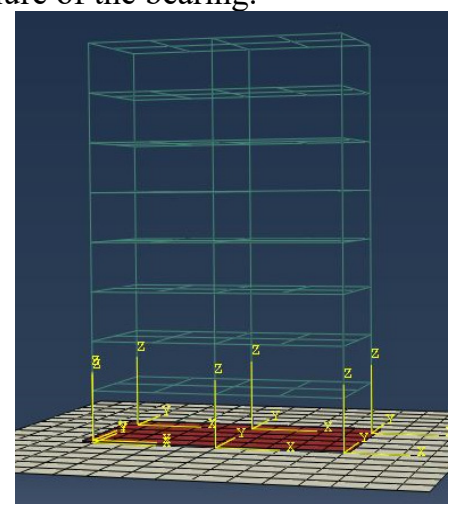

Fig.4. Isolated structure finite element model

\subsection{Element model of the superstructure}

The superstructure uses the B31 space beam element to simulate $^{[10]}$, and the ground is simulated by the S4R shell element. Considering that the input of seismic waves is borne by the ground, the elastic modulus of the ground components is increased to reduce the acceleration loss to a minimum. The main section size and concrete strength grade of frame beam and frame column are shown in Table 4. 
Table 4. Parameters of frame beam column

\begin{tabular}{|c|c|c|}
\hline & Section size & Concrete strength grade \\
\hline Frame beam & $400 \times 850$ & C30 \\
\hline Secondary beam & $400 \times 750$ & C30 \\
\hline Frame column & $600 \times 600$ & C30 \\
\hline
\end{tabular}

\subsection{Element model of the upper plate}

The S4R shell element is used to simulate the upper plate of the isolation layer and the damage of concrete is taken into account. The thickness of the upper layer of the isolation layer is $0.3 \mathrm{~m}$, and C30 concrete is adopted, and the damage model provided by Abaqus is shown in Table 5-7.

Table 5. Plastic parameters of concrete $\mathrm{C} 30$

\begin{tabular}{|c|c|c|c|c|}
\hline $\begin{array}{c}\text { Dilation } \\
\text { Angle }\end{array}$ & Eccentricity & $f_{\mathrm{b} 0} / f_{\mathrm{c} 0}$ & $K$ & $\begin{array}{c}\text { Viscosity } \\
\text { Parameter }\end{array}$ \\
\hline 38 & 0.1 & 1.16 & 0.66667 & 0.0005 \\
\hline
\end{tabular}

Table 6. Compression and tensile properties of concrete C30

\begin{tabular}{|c|c|c|c|}
\hline \multicolumn{2}{|c|}{ Compression properties } & \multicolumn{2}{c|}{ Tensile properties } \\
\hline $\begin{array}{c}\text { Yield stress } \\
/ \mathrm{kPa}\end{array}$ & $\begin{array}{c}\text { Inelastic } \\
\text { strain }\end{array}$ & $\begin{array}{c}\text { Yield stress } \\
/ \mathrm{kPa}\end{array}$ & $\begin{array}{c}\text { Inelastic } \\
\text { strain }\end{array}$ \\
\hline 24019 & 0 & 1780 & 0 \\
\hline 29208 & 0.0004 & 1460 & 0.0001 \\
\hline 31709 & 0.0008 & 1110 & 0.0003 \\
\hline 32358 & 0.0012 & 960 & 0.0004 \\
\hline 31768 & 0.0016 & 800 & 0.0005 \\
\hline 30379 & 0.0020 & 536 & 0.0008 \\
\hline 28507 & 0.0024 & 359 & 0.0010 \\
\hline 21907 & 0.0036 & 161 & 0.0020 \\
\hline 14897 & 0.0050 & 73 & 0.0050 \\
\hline 2953 & 0.0100 & 4 & 0.0100 \\
\hline
\end{tabular}

Table 7. Compression and tensile damage parameters of concrete $\mathrm{C} 30$

\begin{tabular}{|c|c|c|c|}
\hline \multicolumn{2}{|c|}{ Compression damage parameters } & \multicolumn{2}{c|}{ Tensile damage parameters } \\
\hline $\begin{array}{c}\text { Damage } \\
\text { Parameter }\end{array}$ & $\begin{array}{c}\text { Inelastic } \\
\text { Strain }\end{array}$ & $\begin{array}{c}\text { Damage } \\
\text { Parameter }\end{array}$ & $\begin{array}{c}\text { Inelastic } \\
\text { Strain }\end{array}$ \\
\hline 0 & 0 & 0 & 0 \\
\hline 0.1299 & 0.0004 & 0.30 & 0.0001 \\
\hline 0.2429 & 0.0008 & 0.55 & 0.0003 \\
\hline 0.3412 & 0.0012 & 0.70 & 0.0004 \\
\hline 0.4267 & 0.0016 & 0.80 & 0.0005 \\
\hline 0.5012 & 0.0020 & 0.90 & 0.0008 \\
\hline 0.5660 & 0.0024 & 0.93 & 0.0010 \\
\hline 0.7140 & 0.0036 & 0.95 & 0.0020 \\
\hline 0.8243 & 0.0050 & 0.97 & 0.0030 \\
\hline 0.9691 & 0.0100 & 0.99 & 0.0050 \\
\hline
\end{tabular}

\subsection{Selection of seismic waves}

In the analysis, the El Centro wave is used as the input ground motion. The El Centro wave has a greater response in the middle frequency band, and the predominant period is $0.56 \mathrm{~s}$, which is mainly applicable to site of Class II. Through many trial calculations, the reaction of the structure in the front $15 \mathrm{~s}$ has been representative, so in the later calculation, the gravity action time $3 \mathrm{~s}$ and the earthquake action time $15 \mathrm{~s}$ are considered, that a total of $18 \mathrm{~s}$ is used for the simulation analysis. The acceleration of the seismic wave is shown in Figure 5.

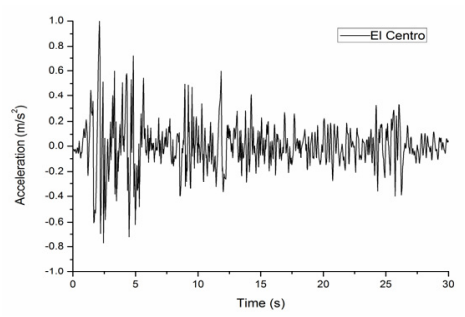

Fig.5 El Centro Wave

\section{Analysis of numerical simulation results}

In the numerical simulation analysis, the El Centro wave is used as the input ground motion. The El Centro wave has a greater response in the middle frequency band, and the predominant period is $0.56 \mathrm{~s}$, which is mainly applicable to site of Class II. Six working conditions are adopted, as shown in Table 8. The vertical displacement, the upper plate damage, peak acceleration of each floor, and the displacement between floors are calculated and analyzed.

Table 8. Working condition

\begin{tabular}{|c|c|c|c|c|}
\hline $\begin{array}{c}\text { Working } \\
\text { condition }\end{array}$ & $\begin{array}{c}\text { Peak } \\
\text { acceleration }\end{array}$ & $\begin{array}{c}\text { failure } \\
\text { bearing }\end{array}$ & $\begin{array}{c}\text { Failure } \\
\text { location }\end{array}$ & $\begin{array}{c}\text { Horizontal } \\
\text { deformation }\end{array}$ \\
\hline 1 & $1.1 \mathrm{~g}$ & none & no & $300 \%-350 \%$ \\
\hline 2 & $1.2 \mathrm{~g}$ & all & whole & $>350 \%$ \\
\hline 3 & $1.1 \mathrm{~g}$ & 1 & edge & $>250 \%$ \\
\hline 4 & $1.1 \mathrm{~g}$ & 2 & middle & $>250 \%$ \\
\hline 5 & $1.1 \mathrm{~g}$ & $1 、 4$ & edge & $>250 \%$ \\
\hline 6 & $1.1 \mathrm{~g}$ & $2 、 5$ & middle & $>250 \%$ \\
\hline
\end{tabular}

\subsection{Comparison of vertical displacement of isolation layer}

When the deformation of all or part of the isolation bearing exceeds the limit and enters the failure state, the isolation layer is destroyed and vertical compression displacement is generated. The situation before and after the collapse of the isolation layer is shown in Figure 6 and the vertical displacement of the isolation layer under different working conditions is shown in Table 9.

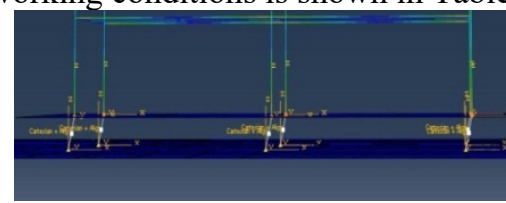

(a) Before

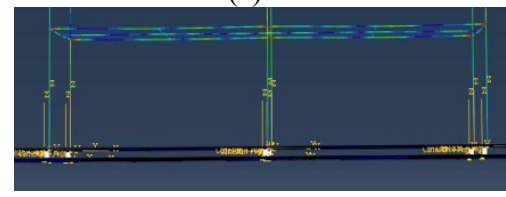

(b) After

Fig.6. Vertical displacement of isolation layer before and after failure 
Table 9. Vertical displacement of isolation layer in different working condition

\begin{tabular}{|c|c|}
\hline $\begin{array}{c}\text { Number of } \\
\text { working condition }\end{array}$ & $\begin{array}{c}\text { Vertical displacement of } \\
\text { isolation layer } / \mathrm{m}\end{array}$ \\
\hline 1 & $\backslash$ \\
\hline 2 & 0.726 \\
\hline 3 & 0.069 \\
\hline 4 & 0.028 \\
\hline 5 & 0.129 \\
\hline 6 & 0.035 \\
\hline
\end{tabular}

Compared with working condition 3 and 4, 5 and 6 , it can be concluded that the impact on vertical displacement of isolation layer of the edge bearing failure on the isolation layer is larger than that of intermediate bearing. At the same time, comparing the working condition 3 and 5, 4 and 6 , it can be concluded that the more isolation bearing fail, the greater the vertical displacement of the isolation layer is, whether at the edge or in the middle.

\subsection{Comparison of tensile damage of the upper plate of the isolation layer}

The damage condition of the upper layer of the isolation layer in working condition 2-6 is shown in Figure 7, and the damage factors in each condition are listed in Table 10 .

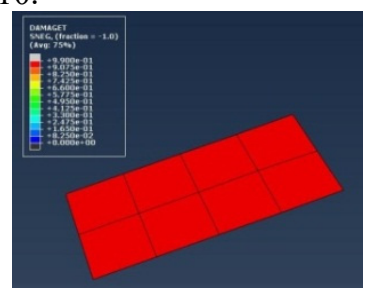

(a) Working condition 2

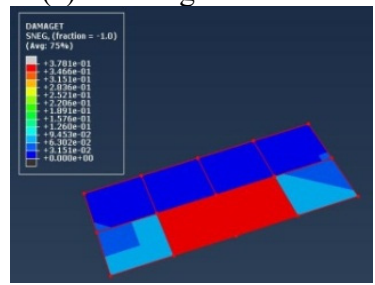

(c) Working condition 4

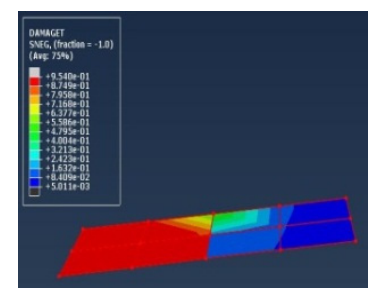

(b) Working condition 3

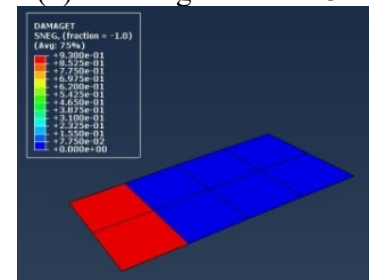

(d) Working condition 5

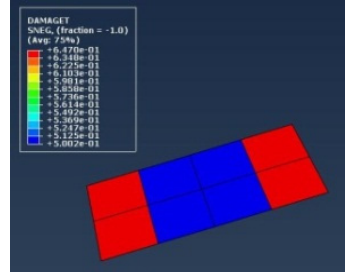

(e) Working condition 6

Fig.7. Tension state of upper plate

Table.10. The tensile damage factor of the upper plate

\begin{tabular}{|c|c|c|}
\hline $\begin{array}{c}\text { Working } \\
\text { condition }\end{array}$ & $\begin{array}{c}\text { Damage } \\
\text { factor }\end{array}$ & $\begin{array}{c}\text { Whether or not to } \\
\text { exceed the limit state }\end{array}$ \\
\hline 1 & $\backslash$ & $\backslash$ \\
\hline 2 & $0.9075 \sim 0.99$ & Exceeding \\
\hline 3 & $0.8749 \sim 0.954$ & Partially Exceeding \\
\hline 4 & $0.3466 \sim 0.3781$ & Not Exceeding \\
\hline 5 & $0.8525 \sim 0.93$ & Partially Exceeding \\
\hline 6 & $0.6348 \sim 0.647$ & Not Exceeding \\
\hline
\end{tabular}

It can be found in table 10 that the damage of the upper plate is the most serious when all the isolation bearings are destroyed, and the damage of the edge bearing makes the upper plate partially exceed the tension limit of concrete, but the damage of the edge bearing is not. Comparing the working condition 3 and 5, 4 and 6 , it can be concluded that the more edge bearing fail, the smaller the damage factor is, but the more intermediate bearing fail, the greater the damage factor is.

\subsection{Comparison of the peak acceleration}

The peak acceleration of each floor under different conditions is shown in Figure 8 and Table 11.

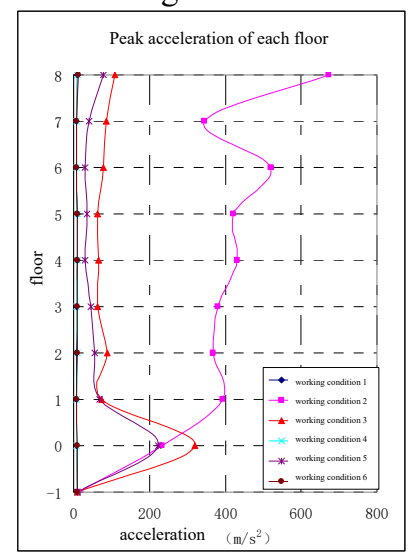

Fig.8. Peak acceleration of each floor

Table.11. Peak acceleration of each floor

\begin{tabular}{|c|c|c|c|c|c|}
\hline \multirow{2}{*}{$\begin{array}{c}\text { Working } \\
\text { condition }\end{array}$} & \multicolumn{5}{|c|}{ Peak acceleration of each floor $/\left(\mathrm{m} / \mathrm{s}^{2}\right)$} \\
\cline { 2 - 6 } & $-1 \mathrm{~F}$ & $0 \mathrm{~F}$ & $1 \mathrm{~F}$ & $2 \mathrm{~F}$ & $3 \mathrm{~F}$ \\
\hline 1 & 11.00 & 8.09 & 7.53 & 8.42 & 8.53 \\
\hline 2 & 12.00 & 233.87 & 392.76 & 369.24 & 381.96 \\
\hline 3 & 11.00 & 319.54 & 72.45 & 89 & 63.15 \\
\hline 4 & 11.00 & 8.73 & 7.34 & 9.22 & 8.04 \\
\hline 5 & 11.00 & 223.03 & 69.3 & 55.66 & 44.72 \\
\hline 6 & 11.00 & 9.16 & 8.73 & 10.34 & 7.4 \\
\hline \multirow{2}{*}{$\begin{array}{c}\text { Working } \\
\text { condition }\end{array}$} & $4 \mathrm{~F}$ & $5 \mathrm{~F}$ & $6 \mathrm{~F}$ & $7 \mathrm{~F}$ & $8 \mathrm{~F}$ \\
\hline 1 & 9.50 & 9.45 & 8.48 & 8.30 & 10.62 \\
\hline 2 & 430.99 & 422.83 & 519.38 & 345.81 & 672.03 \\
\hline 3 & 65.13 & 62.28 & 79.26 & 85.43 & 108.96 \\
\hline 4 & 9.5 & 9.45 & 8.48 & 8.3 & 10.78 \\
\hline 5 & 31.13 & 35.77 & 29.75 & 40.19 & 79.94 \\
\hline 6 & 7.85 & 9.29 & 6.89 & 9.08 & 13.99 \\
\hline
\end{tabular}

Comparing the various working conditions, it can be concluded that the acceleration of each layer is the largest when the isolation bearing is completely destroyed, and the peak acceleration of the top floor is the largest too, which can reach $673.03 \mathrm{~m} / \mathrm{s}^{2}$. The impact on acceleration of each floor of the edge bearing failure on the isolation layer is larger than that of intermediate bearing. Comparing the working condition 3 and 5, 4 and 6 , it can be concluded that the more edge bearing fail, the smaller the acceleration is, but the more intermediate bearing fail, the greater the acceleration is.

\subsection{Comparison of the interlayer displacement}


The interlayer displacement of each floor under different conditions is shown in Figure 9 and Table 12.

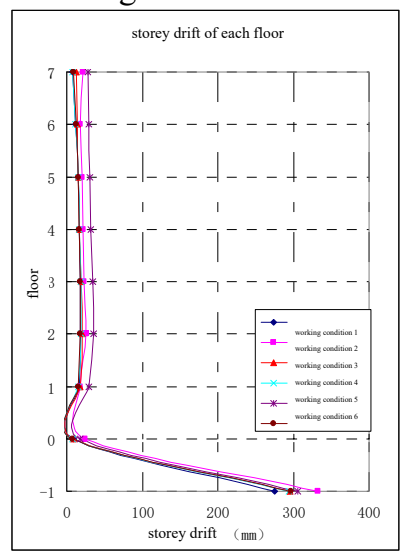

Fig.9. Interlayer displacement of each floor

Table.12. Interlayer displacement of each floor

\begin{tabular}{|c|c|c|c|c|c|}
\hline \multirow{2}{*}{$\begin{array}{c}\text { Working } \\
\text { condition }\end{array}$} & \multicolumn{5}{|c|}{ Interlayer displacement of each floor $/ \mathrm{mm}$} \\
\cline { 2 - 6 } & $-1-0 \mathrm{~F}$ & $0-1 \mathrm{~F}$ & $1-2 \mathrm{~F}$ & $2-3 \mathrm{~F}$ & $3-4 \mathrm{~F}$ \\
\hline 1 & 275.59 & 8.59 & 16.35 & 18.19 & 18.29 \\
\hline 2 & 332.56 & 24.36 & 17.21 & 25.06 & 22.8 \\
\hline 3 & 294.95 & 8.88 & 17.67 & 20.37 & 19.50 \\
\hline 4 & 293.64 & 7.77 & 15.92 & 18.98 & 18.62 \\
\hline 5 & 305.94 & 17.88 & 29.8 & 35.17 & 34.66 \\
\hline 6 & 297.34 & 8.13 & 15.35 & 18.13 & 17.48 \\
\hline \multirow{2}{*}{$\begin{array}{c}\text { Working } \\
\text { condition }\end{array}$} & \multicolumn{5}{|c|}{ Interlayer displacement of each floor $/ \mathrm{mm}$} \\
\cline { 2 - 6 } & $4-5 \mathrm{~F}$ & $5-6 \mathrm{~F}$ & $6-7 \mathrm{~F}$ & $7-8 \mathrm{~F}$ & $4-5 \mathrm{~F}$ \\
\hline 1 & 17 & 14.87 & 11.49 & 7.92 & 17 \\
\hline 2 & 21.15 & 20.69 & 18.38 & 22.24 & 21.15 \\
\hline 3 & 17.18 & 15.68 & 14.32 & 12.87 & 17.18 \\
\hline 4 & 16.8 & 14.87 & 11.49 & 7.92 & 16.8 \\
\hline 5 & 31.87 & 30.26 & 29.12 & 27.87 & 31.87 \\
\hline 6 & 16.8 & 15.2 & 12.19 & 8.47 & 16.8 \\
\hline
\end{tabular}

Comparing the various working conditions, it can be concluded that the interlayer displacement of each layer is the largest when the isolation bearing is completely destroyed, which can reach $673.03 \mathrm{~m} / \mathrm{s}^{2}$ and is 1.21 times the displacement of the undamaged. The impact on interlayer displacement of each floor of the edge bearing failure on the isolation layer is larger than that of intermediate bearing, and the more bearing fail, the greater the interlayer displacement is. Even sometimes, the damage of intermediate bearing can also reduce some of the interlayer displacement, so as to achieve the effect of damping.

\section{Summary}

In this paper, the elastic behavior, plastic behavior and damage behavior provided by the connector element in Abaqus are used to simulate the isolation bearing with multiple stiffness in the horizontal direction and apply it to the numerical simulation of an 8 layer isolation structure to analyze the dynamic response of the isolation layer and the superstructure under different working conditions. The main results are as follows.

(1) When the deformation of all or part of the isolation bearing exceeds the limit and enters the failure state, the isolation layer is destroyed, and vertical compression displacement is generated. At the same time, the upper plate of isolation layer may partially all whole exceed the tension limit of concrete, cause damage and magnify the acceleration and interlayer displacement of superstructure.

(2) When the bearing of the isolation layer is destroyed, the whole structure will be most affected, and the impact of the edge bearing on the isolation layer damage, the upper plate damage of the isolation layer, the acceleration of the upper structure and the interlayer displacement is larger than that of the middle bearing. Therefore, it is suggested that the redundancy of the edge bearings should be increased and protection measures should be provided in the design.

(3) The number of bearings damaged will affect the analysis results, but the influence rules of the edge support and the middle bearing are different. With the increase of the number of bearing failure, the vertical displacement of the isolation layer, the tensile damage of the upper plate and the interlayer displacement of the upper structure will be larger. However, for acceleration, the more edge bearing fail, the smaller the acceleration is, but the more intermediate bearing fail, the greater the acceleration is.

(4) The damage of intermediate bearing can reduce some of the interlayer displacement, so as to achieve the effect of damping.

\section{References}

1. Civil structure group of Tsinghua University, civil construction group of Southwest Jiao Tong University, structure group of Beijing Jiaotong University. Earthquake damage analysis of buildings in Wenchuan earthquake [J]. Journal of architectural structure, 2008, 29 (4): 1-9.

2. Damage Analysis and Numerical Simulation Research of Isolation Bearings. Yue Ren, Ruidong Wang etc.(paper has been accepted)

3. Nakanishi Ryuji et al. Fragility evaluation of base-isolated building Part1: Evaluation of fragility curve considering bumping against retaining wall [J]. Architectural Institute of Japan, 2007.8, 941-942.

4. ENDO Manabu et al. Fragility evaluation of base-isolated building Part2: Evaluation of fragility curve considering bumping against retaining wall [J]. Architectural Institute of Japan, 2007.8, 943-944.

5. Zhuo Zhuang et al. Finite element analysis and application based on ABAQUS [M]. Beijing: Tsinghua university press, 2009.1.

6. Zhaoyuan Chen, Jiaru Qian. Analysis and design of anti-collapse of building and engineering structure [M]. Beijing: China Architecture\& Building Press, 2010.12: 280-289.

7. Zhaoyuan Chen, Qiaru Qian. Analysis and design of collapse resistance for architecture and engineering structures [M]. Beijing: China Construction Industry Press, 2010.12:280-289. 
8. Ming Guo. Damage factor research and application of concrete plastic damage model $[\mathrm{J}]$. Journal of civil engineering and management, 2011, 28 (3): 128-132.

9. Zheng Lee et al. Effect of concrete damage model parameters on seismic response of reinforced concrete piers $[\mathrm{J}]$. Journal of Beijing University of Technology, 2011, 37 (1): 18-24.

10. Qinghua Huang, Spatial Collapse Response Analysis of Reinforced Concrete Frame Structures under Earthquake [D].Ph.D. Dissertation, Tongji University, 2006. 